\title{
EJNSO
}

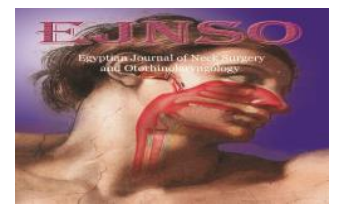

\section{Evaluation of intranasal mometasone furate in the treatment of children with otitis media with effusion}

\author{
Somaya Hamed Abdel Galil ${ }^{1}$, Hamza El Shafiey Ahmed ${ }^{2}$, Ahmed Abdel Aleem Abdel \\ $\mathrm{Wahab}^{2}$ \\ ${ }^{1}$ Otorhinolaryngology Department Dairut central Hospital -Dairut. Assiut \\ 2. Otorhinolaryngology department, Faculty of Medicine- Assiut University
}

\begin{abstract}
:
Introduction: Otitis media with effusion (OME) is the most common cause of acquired hearing loss in children. Conventional medical therapy has been tried for OME including antibiotics, decongestants, antihistamines, local and systemic steroids. The results of these trials are quite controversial. Intranasal mometasone furate is a powerful anti-inflammatory that has been thought to benefit in the treatment of OME.

Objective: To evaluate the possible role of mometasone furate in the treatment of children with OME.

Patients and methods: Sixty children having OME with significant hearing loss were included in the study. They were divided into two groups (A \& B) each composed of 30 children. Patients in group A were given intranasal mometasone furate $100 \mathrm{mcg} / \mathrm{day}, 1 \mathrm{puff}$ in each nostril for 6 weeks. Patients in group B were subjected to watchful waiting without any medication for the same period. Clinical and audiological follow up was done after 6 weeks.

Results: The overall results showed that there is no significant difference in improvement of OME between the 2 groups.

Conclusions: Administration of intranasal mometasone furate for children with OME is not superior to watchful waiting.

Key words: Otitis media with effusion, Mometasone furate, Watchful waiting.
\end{abstract}

\section{$\underline{\text { Introduction }}$}

Otitis media with effusion is defined as the presence of fluid in the middle ear without signs or symptoms of acute ear infection. The condition is common enough to be called "occupational hazard of early childhood. ${ }^{1}$ About 2.2 million diagnosed episodes of OME occur annually in the United States with a cost of around $\$ 4.0$ billion. ${ }^{2}$

Although many OME cases resolve spontaneously, referral rates from primary care centers for surgery (grommets) remains high. $^{3}$ The treatment of OME is diverge. The lines of treatment range from observational treatment, medical treatment and surgical treatment. Intranasal mometasone furate has been long thought to be a line of medical therapy for OME. ${ }^{4}$ Their anti-inflammatory effects on post-nasal space, peri tubal lymphatic tissue \& on the encroaching adenoids on the Eustachian tube (ET), have all been suggested as possible mechanism of action. ${ }^{5}$ 


\section{Patients and Methods:}

\section{Patients:}

The study included 60 children with OME with significant hearing loss to whom myringotomy was scheduled. Diagnosis of OME was both clinical and audiological (flat tympanogram). Patients were divided into two groups (A \&B). Each group was composed of 30 children. Group A was given intranasal mometasone furate $100 \mathrm{mcg} / \mathrm{day}, 1$ puff in each nostril in the morning for 6 weeks. Group B was subjected to watchful waiting without any medication for the same period of time. Clinical and audiological follow up was done after 6 weeks.

-Inclusion criteria: children with bilateral OME and significant hearing loss who were candidates for surgery.

-Exclusion criteria: patients with unilateral OME, previous surgery for OME, craniofacial anomalies and cleft palate and patients with mixed hearing loss.

\section{Clinical and audiological assessment:}

Each patient was subjected to history taking, clinical examination tympanometry and audiometry at the beginning of the study and after 6 weeks. Soft tissue X-ray lateral view nasopharynx was asked for when adenoid enlargement was suspected.

-Tympanometric results were distinguished into four grades as classified by ${ }^{6}$ :

- Type A, normal curve (pressure 50/99 H2O);

- Type C1 (negative pressure 100/199 $\mathrm{mm} \mathrm{H} 2 \mathrm{O})$;

- Type C2 (negative pressure 200/394 $\mathrm{mmH} 2 \mathrm{O})$;

- Type B (flat curve).

-Audiologic evaluation: Pure tone audiometry was carried out to evaluate the degree of hearing loss in children older than 6 years old Younger children were subjected to free field evaluation.
During a diagnostic hearing evaluation, the average pure tone is measured at different frequencies $(0.5,1,2$, and 4 $\mathrm{kHz}$ ) in each ear. ${ }^{7}$ These frequencies are typical for normal conversational speech.

-X-ray nasopharynx lateral view: We have used Cohen and Konak method ${ }^{8}$ for detection and grading of adenoid hypertrophy. Patients then were categorized into one of three groups:

1 Normal (airway-to-soft-palate ratio $\geq 1$ );

2 Mild-to-moderate hypertrophy (airway-to-soft-palate ratio between 0.5 and 1$)$;

3 Severe hypertrophy (airway-to-softpalate ratio $<0.5)(8)$.

According to cohen $\&$ Konak $^{8}$ severe hypertrophy of adenoids is significant while normal, mild and moderate hypertrophy is insignificant.

Comparison between the two groups was done through collecting data prestudy and at the end of the study. Also, comparison between the pre- and poststudy data was done for each group separately.

The study had been carried out in outpatient clinic of the department of otolaryngology at Assiut university hospital. It was approved by the Institutional Ethics and Research Committee of the Faculty of Medicine, Assiut University, Assiut, Egypt. The whole study was explained to the parents of the children and a written consent was taken

\section{Statistical analysis:}

The collected data were revised, organized, tabulated and statistically analyzed using statistical package for social sciences (SPSS) version 23.0 for windows. Data are presented as the Mean \pm standard deviation (SD), frequency, and percentage. The level of significance was accepted if the $\mathrm{P}$ value $<0.05$ 


\section{Results:}

They were 34 boys (56.7\%) and 26 girls $(43.3 \%)$. The age of the patients ranged from 3 to 10 years, mean age in study group (4.2 \pm 2.23$)$ and mean age in control group $(3.9 \pm 1.87)$ years.

Patients who did not improve by the end of the study (14 patients in study group A and 18 patients in control group B) were scheduled for surgical intervention.

-Two patients (one patient in each group) were subjected to myringotomy and dry tap was found and no ventilation tubes were placed.

-Myringotomy was done for the remaining 13 patients in study group and 17 patients in control group. Mucoid fluid was the contents of the ME. Aspirated and ventilation tubes were placed. Adenoidectomy was done when the adenoid size was significantly large (17 patients in group A and 14 in group B).

Table (1): Comparison between patients of group A and B as regard ear symptoms:

\begin{tabular}{|c|c|c|c|c|c|}
\hline & \multicolumn{2}{|c|}{ Group A $(n=30)$} & \multicolumn{2}{|c|}{ Group B $(\mathbf{n}=30)$} & \multirow[b]{3}{*}{ P-value } \\
\hline & At week 0 & At week 6 & At week 0 & At week 6 & \\
\hline & No. of patients & $\begin{array}{l}\text { No. and \% } \\
\text { improved }\end{array}$ & No. of patients & $\begin{array}{l}\text { No. and \% } \\
\text { Improved }\end{array}$ & \\
\hline Hearing loss & 30 & $16(53.3 \%)$ & 30 & $12(40 \%)$ & 0.301 \\
\hline Earache & 10 & $4(40 \%)$ & 8 & $3(37.5 \%)$ & 0.671 \\
\hline DLD & 8 & $2(25 \%)$ & 5 & $1(20 \%)$ & 0.835 \\
\hline
\end{tabular}

Table 2 Comparison between the 2 groups regarding the hearing threshold levels

\begin{tabular}{|l|c|c|}
\hline & $\begin{array}{c}\text { Group A } \\
\text { (nasal steroid) }\end{array}$ & $\begin{array}{c}\text { Group B } \\
\text { watchful waiting }\end{array}$ \\
\hline $\begin{array}{l}\text { Threshold of hearing at start of the } \\
\text { study in dB }\end{array}$ & $38.5 \pm 3.75$ & $39.7 \pm 3.92$ \\
\hline Threshold At week 6 & $23.7 \pm 2.34$ & $26.5 \pm 2.56$ \\
\hline Degree of improvement & 14.8 & 13.2 \\
\hline P-Value & \multicolumn{2}{|c|}{0.301} \\
\hline
\end{tabular}

Table 3 Comparison between study and Control groups as regard tympanometric curves at the end of week 6 .

\begin{tabular}{|c|c|c|c|c|c|}
\hline \multirow{2}{*}{ Tympanometric curve } & \multicolumn{2}{|c|}{ Group A } & \multicolumn{2}{c|}{ Group B } & \multirow{2}{*}{ P-value } \\
\cline { 2 - 5 } & No. of ears & $\%$ & No. of ears & \% & \\
\hline Type B & 28 & 46.7 & 36 & 60.0 & \\
\cline { 1 - 5 } Type C1 & 14 & 23.3 & 10 & 16.7 & \multirow{2}{*}{0.301} \\
\hline Type C2 & 10 & 16.7 & 8 & 13.3 & \\
\hline Type A & 8 & 13.3 & 6 & 10 & \\
\hline
\end{tabular}




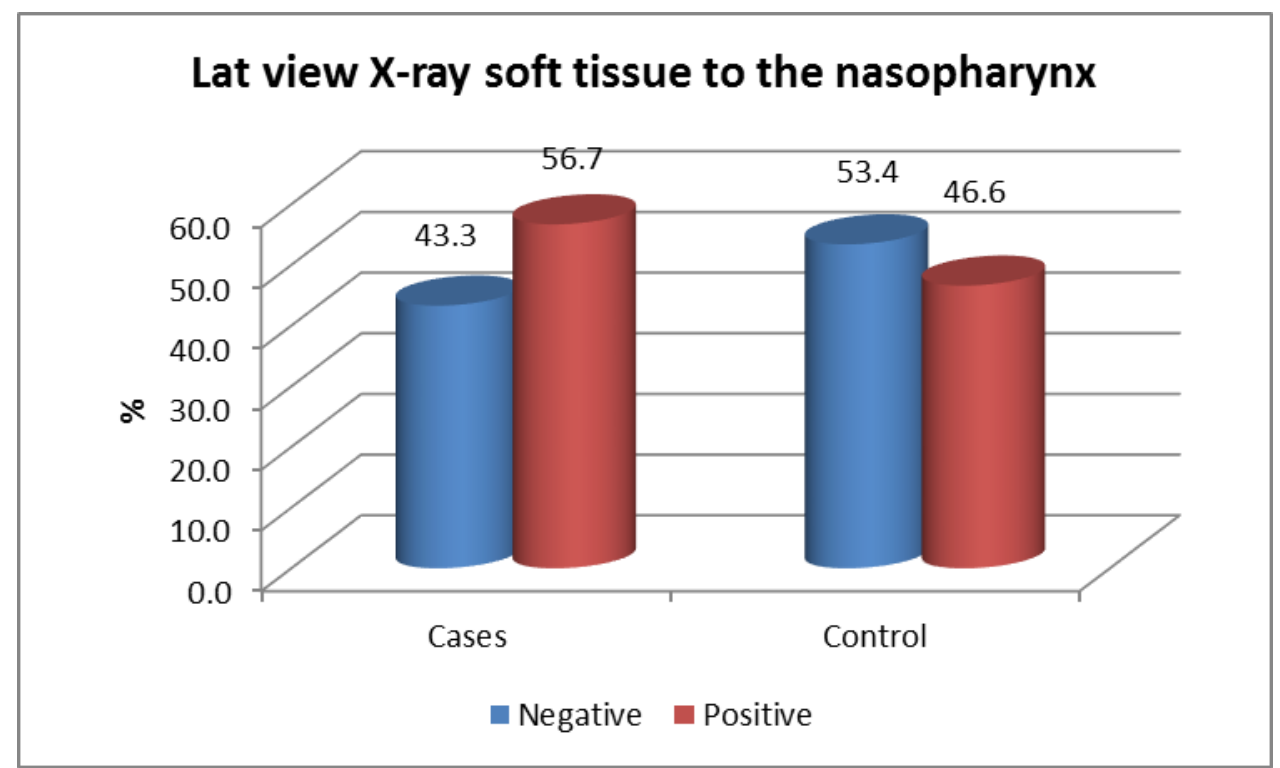

Figure1: Significant Histogram comparing adenoidal hypertrophy by X-ray lateral view soft tissue to the nasopharynx.

Table 4: Comparison between Patient and Control group as regard nasal symptoms.

\begin{tabular}{|c|c|c|c|c|c|}
\hline & \multicolumn{2}{|c|}{ Group A $(n=30)$} & \multicolumn{2}{|c|}{ Group B $(n=30)$} & \\
\hline & Pretreatment & At week 6 & Pretreatment & At week 6 & \\
\hline \multirow[t]{2}{*}{ Nasal discharge } & $\begin{array}{l}\text { No. of } \\
\text { Patients } \\
\text { with }\end{array}$ & $\begin{array}{c}\text { Improved } \\
\text { No. and \% }\end{array}$ & $\begin{array}{l}\text { No. of patients } \\
\text { with }\end{array}$ & $\begin{array}{l}\text { Improved } \\
\text { No. and \% }\end{array}$ & P. Value \\
\hline & 17 & $13(76.5 \%)$ & 12 & $2(16.7 \%)$ & 0.005 \\
\hline $\begin{array}{c}\text { Nasal } \\
\text { obstruction }\end{array}$ & 17 & $15(88.2 \%)$ & 14 & $3(21.4 \%)$ & $<0.001 * *$ \\
\hline $\begin{array}{l}\text { Nasal itching } \\
\text { and sneezing }\end{array}$ & 12 & $10(83.3 \%)$ & 9 & $3(33.3 \%)$ & 0.001 \\
\hline
\end{tabular}

Table 5: Adverse effects experienced during the study

\begin{tabular}{|c|c|c|}
\hline Adverse effect & Group A & Group B \\
\hline (AOM) & 2 cases of AOM with otorrhea & 1 case without otorrhea \\
Stinging in nose & 0 & 0 \\
Nose bleed & 0 & 0 \\
\hline
\end{tabular}




\section{Discussion :}

OME has been defined as the presence of non-purulent fluid in the middle ear, classically without signs or symptoms of acute ear infection. ${ }^{9}$

Delayed language and speech development are not common with OME. To appear, such a delay requires relatively long time and a very young child -where the curve of speech and language acquisition is upmost. It also requires a bilateral disease. ${ }^{1,10}$

The nasal and ME mucosa are continuous with each other through the ET mucosa, and most middle ear infections have the nose as its source of the noxious material or microorganism. It is also believed that the middle ear is affected to some extent with the various pathologic conditions of the nose. 11-16 The mometasone furate we used in the study was administered through the nose. That is why we studied the nasal symptoms pre- and post-treatment (table 4).

We have recorded the clinical effects of nasal mometasone on the ear and compared them with the watchful waiting (table 1). More than half the patients in the study group noticed subjective improvement of their hearing, denoting improvement in the OME. The improvement was less than that in the earache and least (one in four) in the delayed language disorder (DLD). It is well known that DLD needs relatively long time to develop and longer time to improve. In our study, we evaluated the patients after 6 weeks of treatment (or observation) which is a relatively short time for delayed speech and language to improve even with improved OME .

Different studies have tried to evaluate the role of different kinds of nasal steroids on the course of OME in children. Most of these studies reported success rate in improving the condition around 50\%. 11-20 One study has compared local steroid with systemic steroids and found no significant difference between the two ways of steroid administration. ${ }^{15}$ Other study compared nasal steroid with antibiotic on one side with antibiotic alone on the other. ${ }^{12}$ The researchers reported more rapid improvement in the combination group at the short-term level. No significant difference was found on long term follow up. We have to stress here that most of these studies, did not use the wait and observe policy as their control. Instead, they included more than one factor in the morbidity in concern (like adenoids in one study) or in the medications to give (like antibiotics). This made their positive results about local steroid uncertain results from our opinion as we will discuss later.

When comparing the results of the watchful waiting as regard ear symptoms with those of the study group no significant differences were found in any of the studied symptoms (table 2) $\mathrm{p}$ value $<0.05$. These results confirmed to us what the systematic reviews and various local and international societies concerned with otology, pediatric ENT and family health have recommended in their medical practice guidelines. ${ }^{1,10,20}$

On trial to make the hearing results more objective, we have evaluated the average hearing threshold through measuring the air conduction thresholds at the beginning of the study and compared them with those at the end of the study (table 2). There was an overall improvement in hearing threshold by $14.8 \mathrm{~dB}$ in the steroid group compared with $13.2 \mathrm{~dB}$ in the control group. Such a small difference was insignificant. Butler and Van Der Voort in their excellent systematic review concluded that steroid may have a quicker resolution of OME in the short-term. On the long term, they found no benefit from either local or 
even systemic steroids and they strongly stood against using them to treat this condition. ${ }^{21}$

It is important here to stress that subjective improvement of hearing does not necessarily mean that the ME returns to its fully normal status. When type B tympanogram is turned to be type $\mathrm{C} 1$-for example- this definitely signifies improvement in the MEE. Not only that, a patient with improved one ear may have overall subjective normal hearing while he or she may have one ear with full effusion. That is the reason we have studied the types of tympanograms we measured by the end of the study for each ear separately for both groups. We found no significant difference in the number of individual ears with each type of tympanogram (table 3). Many authors have reported similar results when evaluating this point. ${ }^{22-25}$

Nasal obstruction and discharge and to a lesser extent sneezing and itching were present in slightly less than half of patients in both the study and control groups. We attributed nasal obstruction and nasal discharge to the adenoidal hypertrophy and nasal allergy. The later was concluded from its symptoms .

We have studied the incidence of significant adenoid hypertrophy (adenoid size obstructing $>50 \%$ of the nasopharynx) (Figure 1). About half of all patients in our study have such a significant hypertrophy. The incidence was slightly more in the study group than in the control group. The exact mechanism(s) that the enlarged adenoids play in the pathogenesis of OME was not entirely understood. The extensive studies from different places in the world linked the causal etiology to some mechanisms like mechanical obstruction of the ET, the effect of bacterial biofilm on the surface of the adenoids to the function of ET. Adenoid local immune regulation as well as Ig E-mediated allergic reaction were also proposed as possible mechanisms. There may be more than one of the previously mentioned mechanism or even all of them, but the link is undeniable. ${ }^{28-31}$

The main positive effect of nasal mometasone was on the nasal symptoms. There was significant improvement in all nasal symptoms that were present at the beginning of the study. Nasal obstruction -for example- has improved in about $90 \%$ of patients. Similar results were observed in sneezing, itching and discharge (table 4). These results are highly significant when compared with those of the control group $\mathrm{P}$ value < 0.001. Local steroids are the gold standard in the treatment of nasal allergy according to all recommendations and guidelines. ${ }^{26-27}$ This is the cause why sneezing and itching had improved markedly. Also, nasal steroids have been studied extensively in the short-term management, long term management, and preventing recurrence of adenoids after adenoidectomy. ${ }^{28-34}$ Local nasal steroids are recommended in the managment of viral and bacterial rhinosinusitis when symptoms are mild to moderate according to the British guidelines (NICE) and American guidelines. $^{1,11,20}$ In summary, steroids improve nasal obstruction through improving the congestion associated with nasal allergy and downsizing the present adenoids. Steroids also improve nasal discharge by controlling allergy and nasal infection .

During these six-week study patients were checked for complications that developed during the course of the study. Two patients in the mometasonefurate group developed acute otitis media with perforation and otorrhea in one ear during the course of upper respiratory tract infection (table 9). Proper local care and systemic 
augmented amoxicillin in the recommended dose were given to these two ears. Perforations healed after about a month and no middle ear effusion was noticed after that in these ears. In the control group one patient came-back suffering from acute otitis media. Local treatment for pain with systemic augmented amoxicillin in the recommended dose was offered to and recovery without residue was the end conclusion of that ear. One may think for the first instance that steroids made the acute otitis media more aggressive when it happened in steroid group compared with that of the control group which passed without perforation. We strongly think that such a small number of patients in the study itself and smaller number of complications are too little to get solid conclusions from.

\section{Conclusion:}

Otitis media with effusion is the most common cause of acquired hearing loss in children. When such a problem is discovered in a child, close follow up should be the primary goal for the physician no rush for surgery is advisable because it is a self-limited problem in most cases.

Local nasal steroids added little for these patients when compared with watchful waiting and if we considered the cost of the drug and their potential side effects, local steroids may be even in the negative side.

The main benefit of local nasal steroids was on the nasal symptoms, so they should be considered to treat nasal problems regardless the presence or absence of effusion

Physicians should adapt to this policy of no treatment and resist the pressure of the parents to prescribe something for these patients.

Myringotomy and ventilation tube insertion - as an operation- has its respectable place as a solution for the problem when hearing loss is significant, when negative effects of effusion on the middle ear and tympanic membrane start to occur.

\section{Financial support and sponsorship:}

No financial support was obtained from any company. When the patients in the study group were able to buy the spray, they bought it while those who were not able to buy, we provided it to them for free.

\section{Conflicts of interest:}

There are no conflicts of interest.

\section{Reference:}

1. RM Rosenfeld, JJ Shin. "Clinical practice guideline: otitis media with effusion executive summary (update) (2016)."

2. GS Takata, LS Chan. "Evidence assessment of the accuracy of methods of diagnosing middle ear effusion in children with otitis media with effusion. (2003). "

3. HES DOH "Hospital Episode Statistics." Grommets.(D15). London., UK. Department of Health (2004).

4. JM Tracy, JG Demain. "Intranasal beclomethasone as an adjunct to treatment of chronic middle ear effusion." (1998).

5. H Yaman, KOZ Turk. "Effectiveness of corticosteroids in otitis media with effusion: an experimental study." (2008).

6. MW El-Anwar, AAF Nofal. "The efficacy of nasal steroids in treatment of otitis media with effusion: a comparative study." (2015).

7. World Health Organization. "Report of the Informal Working Group on Prevention of Deafness and 
Hearing Impairment Programme Planning, 1991."

8. D Cohen and S. Konak. "The evaluation of radiographs of the nasopharynx." (1985)

9. SE Stool, Berg AO. "Managing otitis media with effusion in young children." (1994).

10.RM Rosenfeld, L Culpepper. Clinical practice guideline: Otitis media with effusion. (2004). KM Harmes, RA Blackwood. "Otitis media: diagnosis and treatment." (2013).

11.GL Marseglia, F Pagella ."Increased risk of otitis media with effusion in allergic children presenting with adenoiditis." (2008).

12.N Quaranta, C Milella. "A study of the role of different forms of chronic rhinitis in the development of otitis media with effusion in children affected by adenoid hypertrophy." (2013)

13.D Passali, GC Passali. "Nasal allergy and Otitis media: a real correlation?" (2014).

14.N Quaranta, L Iannuzzi. "Does the type of rhinitis influence development of otitis media with effusion in children?" (2014).

15.X Cheng, H Sheng. "Allergic rhinitis and allergy are risk factors for otitis media with effusion: A metaanalysis." (2017).

16.KW Heo, MJ Kim. "Impact of nasal conditions on chronic otitis media: (2018).

17.AGM Schilder, T Chonmaitree. "Otitis media." Nature Reviews Disease Primers (2016).

18.RM Rosenfeld, L Culpepper. Clinical practice guideline: Otitis media with effusion. (2004).

19.EB Edetanlen, and BD Saheeb "Otitis media with effusion in Nigerian children with cleft palate: incidence and risk factors." (2018).
20.R Khanna, M Lakhanpaul. "Surgical management of otitis media with effusion in children: summary of NICE guidance." (2008).

21.CC Butler, and JH van der Voort "Steroids for otitis media with effusion: a systematic review." (2001).

22. I Williamson, S Beng - "Topical intranasal corticosteroids in 4-11 year old children with persistent bilateral otitis media with effusion in primary care: (2009).

23.SS Menon, $R$ Balakrishnan . "Efficacy of mometasone nasal spray in the treatment of otitis media with effusion in the pediatric age group: (2013).

24.MW El-Anwar, HS Amer . "Effect of central inset pharyngeal flap for velopharyngeal insufficiency on eustachian tube function." (2015).

25.M Anwar, M Abdel-Aziz . "A comparative study of the efficacy of topical nasal steroids versus systemic steroids in the treatment of otitis media with effusion in children." (2015).

26.GK Scadding, SR Durham • "BSACI guidelines for the management of allergic and non-allergic rhinitis." Clinical \& Experimental (2008).

27.AN Greiner, PW Hellings . "Allergic rhinitis." (2011).

28.S Cengel and MU Akyol. "The role of topical nasal steroids in the treatment of children with otitis media with effusion and/or adenoid hypertrophy." (2006).

29.A Chohan, A Lal. "Systematic review and meta-analysis of randomized controlled trials on the role of mometasone in adenoid hypertrophy in children." (2015).

30.YS Yildirim, E Senturk . "Efficacy of nasal corticosteroid in preventing 
regrowth after adenoidectomy."

(2016).

31.MA Bitar, J Nassar. "Is the effect of topical intranasal steroids on obstructive adenoids transient or long-lasting? (2016).

32.B Tuhanioglu and SO ERKAN "Evaluation of the effects of montelukast, mometasone furoate, and combined therapy on adenoid size: (2017).

33.W Liu and RJ Chen "Clinical observation of mometasone furoate nasal spray combined with montelukast sodium in the treatment of adenoid hypertrophy in children." (2017).

34.W Liu, L Zhou. "Combination of mometasone furoate and oxymetazoline for the treatment of adenoid hypertrophy concomitant with allergic rhinitis: (2017). 